\title{
Does Evolutionary Theory Offer Insight into Epistemology, Consciousness, Sex, Race, Religion, Ethics, and the Meaning of Life?
}

\author{
Evolution and the Big Questions: Sex, Race, Religion, and Other Matters, by David N. \\ Stamos. Malden, MA: Blackwell, 2008. viii + Pp. 275. S/b \$38.95
}

Gregory J. Morgan • Tina Singh • Sean Donovan • David J. Watson • Jonathan Boos • John Hu • Cassidy L. DeSchryver • Brittany K. Crosby • Tadas Vilkeliskis •

Brian Worthmann $\cdot$ Steven Sagona

Published online: 17 December 2011

(C) Springer Science+Business Media, LLC 2011

\section{Introduction}

This relatively thin but provocative volume discusses whether evolutionary explanations (often from evolutionary psychology) are useful in understanding some of life's deepest issues, including the foundations of ethics and religion. Each chapter considers a new "Big Question." At the end of each chapter, David Stamos supplies his analysis, which often attempts to overturn pre-Darwinian thinking. The book's strength is its breadth, and its weakness is its lack of depth on some rather thorny issues. It is a stimulating book for students to read and with supplementary additional readings serves successfully as a text for an upper-level philosophy of biology class.

\section{Evolution and Knowledge}

Stamos begins his book by tackling the relationship between evolution and knowledge. He describes how "Cartesian Solipsism," the dominant approach to epistemology in modern

This review is the product of a successful pedagogical experiment in group writing and group editing using Google docs conducted in HPL367 Philosophy of Biology, a course taught at Stevens Institute of Technology in the spring of 2011.

G. J. Morgan $(\bowtie) \cdot$ T. Singh $\cdot$ S. Donovan • D. J. Watson •

J. Boos $\cdot$ J. Hu $\cdot$ C. L. DeSchryver • B. K. Crosby · T. Vilkeliskis •

B. Worthmann $\cdot$ S. Sagona

College of Arts and Letters, Stevens Institute of Technology,

1 Castle Point on Hudson,

Hoboken 07030 NJ, USA

e-mail: gmorgan@stevens.edu philosophy, has become a large stumbling block, for it starts with mind and sense data and "works its way out to the external world" and for that reason is prone to skepticism. As a result of this weakness, many contemporary philosophers have focused their attention on modern science as an epistemological starting point or have undertaken the study of naturalized epistemology. Stamos is specifically interested in discussing the placement of knowledge on an evolutionary foundation, his major topic of focus for the first chapter.

Stamos considers two different approaches in evolutionary epistemology. The first, championed by Michael Bradie, "attempts to account for the cognitive mechanisms in animals and humans through a straightforward extension of the theory of evolution" (p. 16). The second considers the evolutionary epistemology of theories, and attempts to explain the evolution of ideas and scientific theories using models drawn from evolutionary biology.

One of the more interesting and comprehensive parts of the first chapter focuses on Karl Popper insofar as he is a founder and leading advocate of "natural-selection epistemology." Stamos reviews Popper's view of the emergence of life from non-living things as well as the view that the mind gradually evolved or emerged from living things. Popper thought of life as first producing "closed behavioral programs" or rigid DNA-based behavioral programs, and then, over time, natural selection developed these closed processes into "open behavioral programs" that were less rigid and open to more diverse environments. Popper outlines four important steps in the pathway from "open behavioral programs" to genuine learning behavior. The first is direct trial-and-error behavior, which encompasses the development of pain and pleasure. 
The second is "imagined trial-and-error behavior," so that an animal can use memory to play out scenarios in its mind and avoid certain types of plants and animals without risking real interaction with those organisms. The third step is the formation of purposeful actions or ends, such as, hunting, which encompasses most of the goal-seeking behavior of higher animals. The last stage, found only in humans, is the development of language that allows for the full analysis of hypotheses in abstract, general ways. This foundation of knowledge in trial-and-error elimination is a powerful idea, and Stamos seems to be particularly encouraged about how Popper's naturalistic view links humans with the rest of the animal world.

Stamos then considers several different aspects of the human mind that appear to be non- or anti-truth seeking, paying mind to the evolutionary reasons for self-deception, stereotyping, herd mentality, and group think. He suggests that because human minds developed epistemological features along with anti-epistemological features, science has been refined to be a system of checked inquiry adapted to facilitate our truth-seeking tendencies and combat our anti-truthseeking tendencies.

The first chapter includes a brief critique of postmodernism, which for Stamos is the view that everything is a matter of perspective and interpretation and that there are no privileged perspectives or interpretations in an epistemological sense. Stamos felt that it was necessary to "point out what was wrong" with postmodernist arguments. His main idea is that if one dismisses logic and evidence to start with, no amount of logic and evidence will be persuasive. If one gives weight to power politics and motives as postmodernists do, one will invariably commit ad hominum fallacies and lose the power of argumentation to uncover truth. Stamos maintains that, "when it comes to evolution and the big questions one should make an inference to the best explanation on a case by case basis, employing as much evidence and established background theory as necessary, rather than getting caught up on what should be the default position" (p. 42). This quote appropriately sums up how he approaches the various topics of the book.

\section{Evolution of Consciousness and Language}

In the second chapter of his book, Stamos considers the evolution and the development of human consciousness. Before discussing the central topic, he points out the general challenge in understanding consciousness: it is a characteristic that is only introspectively verified and cannot be directly perceived in other individuals. Stamos searches for a definition of consciousness, ultimately coming to a conclusion that the best definition of consciousness needs to explain something deeper than simple language usage. He presents three competing views regarding consciousness: (1) consciousness arose as a direct adaptation resulting in improved reproductive success; (2) consciousness is a byproduct of selection for another characteristic; (3) consciousness is the work of a divine entity that is impossible to explain through material processes. Stamos begins by examining the case for consciousness as a miracle by referencing the views of Oxford theologian Richard Swinburne. He points out key aspects of Swinburne's views, beginning with the distinction between physical and mental events, from which Swinburne concludes that there is no selective advantage for having a mental life. Also, Swinburne claims that while there can exist personal explanations of consciousness, to understand the idea in its entirety can only be explained by God. Stamos then details some problems with Swinburne's argument: notably, the complexity that the inclusion of God generates, and Swinburne's failure to understand the evolutionary benefit of consciousness.

After presenting the case against divine intervention, it is a little disappointing how minimally Stamos discusses the other two views. He presents several interesting ideas about consciousness, but often fails to directly relate them to a specific view about the rise of consciousness through evolution. Stamos discusses the relationship between consciousness and language, most convincingly through his consideration of the Wada test. This test shows that by temporarily anesthetizing the known language center of the brain, consciousness is apparently indistinguishable from the ability to speak. Nonetheless, Stamos conceptually disconnects consciousness from language development. He does so by arguing for varying degrees of consciousness, mentioning dream states and animal consciousness, as well as quoting E.O. Wilson's description of humankind as "the babbling ape." To further explain the idea of degrees of consciousness, Stamos draws an analogy with eyes and eyesight; he claims the eye originated in the animal kingdom at least 40 times, and each instance has allowed for different capabilities. So too there can be different kinds of consciousness Stamos suggests.

Stamos's chapter on evolution and language begins with a description of the what evolutionary psychologists call the "Standard Social Science Model" (SSSM), the view that the brain is a "general purpose learning device," capable of learning a variety of languages. Evolutionary psychologists tend to reject this view in favor of the mind as a set of specific, dedicated, problem solving modules. The chapter introduces the influential views of Noam Chomsky-that the faculty of language is largely innate and "switches" that change specific, superficial features of language are turned either on or off by the environment. This "unconscious knowledge" of language that is hard-wired into humans is dubbed by Chomsky the universal grammar (UG). 
Though Chomsky himself resisted the notion that the UG evolved by natural selection, Stamos begins to explore this possibility by drawing on the work of Steven Pinker and Derek Bickerton. Chomsky claims that the UG came about by "true emergence" rather than traditional Darwinian natural selection, but this claim is dubious because "the probability of the UG and the right vocal anatomy resulting either from a single mutation or a simultaneous combination of mutations is vanishingly small" (p. 72). Stamos outlines Steven Pinker's five similarities between the human language and the trunk of an elephant, citing their uniqueness, complexity, correlation with large head/brain size, evolvability, and the existence of proto- forms of each. Pinker's view, then, is that natural selection is indeed the best explanation of the emergence of language users.

Bickerton similarly lays out an argument for the emergence of language. A "cognitive explosion" occurred nearly 120,000 years ago as a result of a tremendous selective advantage conferred upon the species Homo sapiens due to their successful, syntactical form of protolanguage. He argues that "syntax could not possibly work as a computational device unless its major defining properties were intimately linked and had emerged simultaneously" (p. 86). The chapter's central thesis is that the human capacity for language seems best explained by standard evolutionary principles, Chomsky's views on UG and Bickerton's "creationist" views notwithstanding.

\section{Evolution, Sexuality, and Gender}

In chapter four, Stamos covers four topics: human mating, incest, rape, and homosexuality, but for reasons of space, we only consider the latter two. Stamos discusses rape and how it might be explained, though by no means morally justified, by evolutionary psychology. There are two evolutionary approaches to rape: (1) it is an adaptation that increases reproductive success, and (2) it is a byproduct of other advantageous behaviors. Stamos largely dismisses the second approach and focuses on the work of Michael Ghiglieri, who favors the first approach. Ghiglieri uses statistics to show that most rapists are of low socioeconomic status, an indicator of low reproductive success, and to demonstrate how it might be a condition-dependent trait. However, we think the byproduct theory should not be tossed aside so quickly. A blended theory is also possible. It could be that rape evolved as a byproduct of successful qualities like assertiveness and strength, but is activated by desperate conditions to ensure at least a chance at reproductive success.

Homosexuality appears to be an anomaly in evolution, as one would expect that homosexuals have lower reproductive fitness and homosexual traits to be selected against. Stamos presents three theories for the explanation of the persistence of homosexuality. The first is kin selection-that homosexuals are "altruistic" beings who pass on their genes by increasing the reproductive fitness of those most closely related. In order to confirm this theory, one would need evidence that homosexuals have been more altruistic than heterosexuals in the evolutionary past. The second theory is that homosexuality is a byproduct of an Xlinked gene that increases the reproductive fitness of women by making puberty occur earlier, but this view is controversial even among geneticists. The third is that homosexuality is a misplacement of sexuality. The example Stamos provides to illustrate the third view is ancient Greek society, where because women were closely protected men would often turn to small boys for sex. Misplacement of sexuality arguably explains the ancient Greek system; however, homosexuality still exists in the present social structure, which resembles little of Ancient Greece.

Chapter five covers the topic of evolution and feminism. Stamos draws from the work of many authors, including Simone de Beauvoir, Daphne Patai, Noretta Koertge, Alice Rossi, Susan Okin, and Anne Fausto-Sterling. He explores many different aspects of feminism, including the issues of teaching extreme feminism to young female students and how this affects the culture of feminism; the debate on whether physical and behavioral differences of men and women come from culture or biology; the is/ought gap; Darwin's theory of sexual selection and how it affects the female mindset; the definitions of male, female, and intersexual; and the myth of objective knowledge and "malestream" science.

One of Stamos's stronger arguments is against Okin's argument for the need to minimize gender differences. Okin claims that gender is only a social and cultural construction and that biological determinism should be rejected. She suggests that for the sake of justice, starting with the family and then working up through all of society, job and family roles should be shared equally between men and women. Stamos agrees that gender roles are somewhat flexible but thinks that Okins's suggestion is doomed to fail if there nonetheless exist biologically based physical and behavioral differences between men and women. If it is true that because of a long history of sexual selection there are biological differences between genders, then the best hope for justice in a 50/50 society would be to enact permanent, gender-specific laws to counterbalance the effects of evolution, which would in turn undermine the goal of minimizing gender itself.

Stamos argues against Anne Fausto-Sterling's view that there are at least five "intersexes" and her view that we should think of sexual dimorphism as merely a socially constructed dichotomy. Fausto-Sterling suggests that complete maleness and complete femaleness are just two opposing and extreme sides of a gender continuum. She states that there are not just 
two genders, but an entire range of genders based on hormone production and physical characteristics. Stamos counters that, from an evolutionary perspective, an individual will only ever naturally produce one kind of gamete, which is what defines each gender. There are cases where an individual will develop both male and female sexual characteristics due to an error in gene expression, but the number of true intersex individuals is less than $0.018 \%$ of the population.

Stamos's argument is most tenuous when he extrapolates the findings from a history of sexual selection in lions and peafowl to the behavior of human males and females in bars and internet dating websites. He uses the differences in the way men and women look and act as an example of where culture reflects biology. Peacocks and widowbirds with large tail feathers will get mates more easily, and this is why they have large tail feathers. On the other hand, men and women are looking for someone specific based on their interests, their situation, and desires. We maintain that this is an example where some variation in dating styles is merely cultural. It is quite likely that, unlike birds, not all women are specifically looking for a mate expressly for purposes of having and rearing children, and not all men are looking for women to simply carry on their genes.

\section{Are Human Races Real?}

In chapter six, "Evolution and Race," Stamos considers various arguments concerning whether human races are real. Can we consistently claim that human races don't exist? He claims that some of the pioneers of racial equality who argue that the concept of human race is illegitimate are, in fact, guilty of using groupings like "Australian Aborigine." As he puts it, "no sooner do they kick human races out the front door, they let them in again through the back door" (p. 140). $\mathrm{He}$ cites the ambiguity surrounding the concept of race as the Achilles' heel of the many biologists, anthropologists, and philosophers who have tried to open the eyes of the public to a world without races. Stamos attacks Richard Hernnstein and Charles Murray's work in The Bell Curve. They attempt to show that IQ is heritable, using twin studies, and that IQ is correlated with race. As race is inherited, they conclude that racial differences in IQ are inherited. Stamos argues that they err in their use of heritability, which properly understood is defined only relative to a specific population in a specific environment. Change either the population or the environment and the heritability of IQ can change. Nonetheless, Stamos suggests that there is "nothing inherently mistaken or wrong headed, let alone evil" in supposing there are racial differences in IQ. For Stamos, racial equality is a moral imperative, not a biological fact. He does not consider whether there are some biological facts that should not be investigated.

\section{Evolution of Ethics and Religion}

In one of Stamos's most controversial chapters, he considers the role evolution plays in ethics. He considers ideas from John Alcock, Aristotle, Ruth Benedict, Jeremy Bentham, Charles Darwin, Richard Dawkins, Thomas Hobbes, David Hume, Immanuel Kant, John Locke, John Stuart Mill, G.E. Moore, Thomas Nagel, Plato, John Rawls, W.D. Ross, Michael Ruse, Albert Schweitzer, Peter Singer, Herbert Spencer, Paul Taylor, Robert Trivers, G.C. Williams, E.O. Wilson, and Peter Woolcock. Stamos's approach is to contrast various thinkers against one another to discover ethical truths and whether or not evolution can provide any help.

He covers Social Darwinism, the naturalistic fallacy, natural rights, social constructionism, social and selfish instincts, psychological egoism, sociobiology, reciprocal altruism, noncognitivism, utilitarianism, virtue ethics, and deontology. He ultimately concludes that an absolute theory of ethics is arbitrary and biased; and to avoid these problems would require the principles of evolution to get its feet off the ground; and that any useful, comprehensive theory of ethics must be firmly planted in the realm of evolutionary biology.

One of Stamos's weakest points is an oversimplification based on the "blind men and the elephant" parable to describe how virtue ethics, psychological egoism, deontology, utilitarianism, Rawls' veil of ignorance, and environmental and feministic ethics are simply just parts of a larger normative ethics which has its grounding in evolution. Admittedly it is just a parable, but most of these theories are incompatible in a way that different parts of an elephant are not, and Stamos says little about how one would avoid the incompatibilities. On the other hand, he does end up rejecting ethical absolutism, which may allow him to say various otherwise incompatible ethical theories are all true within restricted domains. This move would be a major revision of standard views in normative ethics.

Stamos' chapter on evolution and religion is arguably the weakest in the book. While in previous chapters Stamos is sometimes guilty of painting his opponents in broad strokes, his ideas are typically coherent and plausible. In this chapter, on the other hand, some of us believe that Stamos is less convincing. His principle weakness is to assume that "divine inspiration," or the truthfulness of religion must compete with evolution's capability to explain it. He seems to assume that the explanation of religion provided by evolutionary psychology implies that one should believe in atheistic evolution.

As he puts it, "Atheistic evolution is simple (it is completely down to earth and involves nothing supernatural), it is objective (it is not what one wants to believe), it is internally and externally consistent with what is known in 
other sciences... it is fruitful... But is it testable?... atheistic evolution is testable. At the genetic level alone, one can conceive of observations that would refute it, such as, a string of sequences in DNA that would be ridiculous to explain by chance or by natural selection" (p. 200).

"Atheistic evolution" is arguably less simple than just "evolution," with nothing new to predict or contribute. As for testability, his point is contestable. Using Ockham's Razor and the inference to the best explanation, both of which he uses to criticize others for beliefs that "don't respect science," one could argue that "atheistic evolution" is at least as falsifiable as "evolution"; and therefore evolution, being the simpler theory, can be inferred as superior to "atheistic evolution." Additionally, Stamos's claim that "theistic evolution" isn't falsifiable and therefore "atheistic evolution" is better science is also questionable. If evolution is found to be false, theistic evolution is falsified, and hence if evolution is falsifiable so is "theistic evolution."

In the final chapter of the book, "Evolution and the Meaning of Life," Stamos discusses the meaning of life from an evolutionary standpoint. He examines the compatibility of evolutionary biology and existentialism in addition to trying to answer the questions of "whether evolution adds any meaning to life, takes away from it, or has no relevance" and "whether we have a basic need, evolved instinctual need, to find meaning of our lives" (p. 215). As in earlier chapters, Stamos takes the viewpoint of evolutionary biology. Arguably, evolution gives humans little choice but to keep playing the game of survival and reproduction. Following later
Richard Dawkins, Stamos suggests that science does not rob the world of meaning, but rather fuels our sense of awe at its grandeur. In the most interesting argument of the chapter, Stamos follows Robert Nozick and argues that the meaning of life is relative to each individual and that one should strive to be connected to other people and things, and that humans can seek the meaning of life through the pursuit of knowledge or through personal relationships. The chapter ends with Stamos arguing that it does not really matter if the universe has a meaning or not, but that evolution has bestowed us with the ability to perform logic and appreciate the fallacy of division. Just because the universe as a whole does not have meaning, it does not follow that no individual person has a meaningful life. What is wrong with existentialism and the SSSM is that they both rely on false conceptions of human nature. Evolutionary thinking suggests that human nature is well described by "statistical norms," and we are not utterly free as Sartre thought, nor do we start as a blank slate as one reading of SSSM asserts.

\section{Conclusion}

In conclusion, this book is definitely worth a read, and Stamos successfully shows how evolutionary thinking has a bearing on the "Big Questions." Aside from weaknesses, which come with covering a vast amount of ground in a slim volume, this book is well worth the time and serves as an excellent introduction to the wide-ranging implications of human evolutionary psychology as seen by a philosopher. 